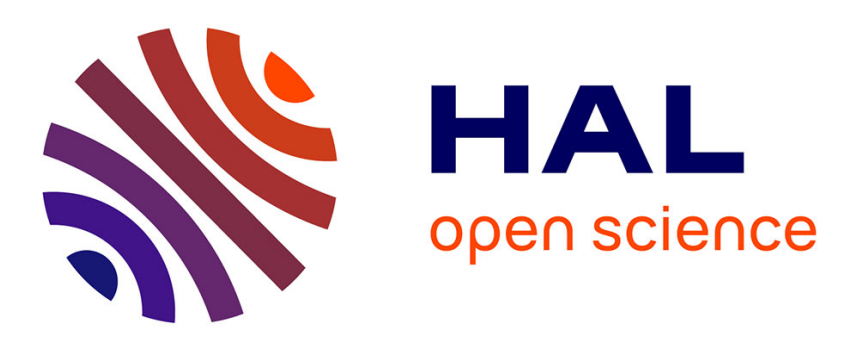

\title{
Identification of novel APOB mutations by targeted next-generation sequencing for the molecular diagnosis of familial hypobetalipoproteinemia
}

Antoine Rimbert, Matthieu Pichelin, Simon Lecointe, Marie Marrec, Solena Le Scouarnec, Elias Barrak, Mikael Croyal, Michel Krempf, Hervé Le Marec, Richard Redon, et al.

\section{To cite this version:}

Antoine Rimbert, Matthieu Pichelin, Simon Lecointe, Marie Marrec, Solena Le Scouarnec, et al.. Identification of novel APOB mutations by targeted next-generation sequencing for the molecular diagnosis of familial hypobetalipoproteinemia. Atherosclerosis, 2016, Equipe 3 Equipe 4 Equipe 5, 250, pp.52-56. 10.1016/j.atherosclerosis.2016.04.010 . hal-01831745

\author{
HAL Id: hal-01831745 \\ https://hal.science/hal-01831745
}

Submitted on 12 Jul 2018

HAL is a multi-disciplinary open access archive for the deposit and dissemination of scientific research documents, whether they are published or not. The documents may come from teaching and research institutions in France or abroad, or from public or private research centers.
L'archive ouverte pluridisciplinaire HAL, est destinée au dépôt et à la diffusion de documents scientifiques de niveau recherche, publiés ou non, émanant des établissements d'enseignement et de recherche français ou étrangers, des laboratoires publics ou privés. 


\title{
Identification of novel $A P O B$ mutations by targeted next-generation sequencing for the molecular diagnosis of familial hypobetalipoproteinemia
}

\author{
Antoine Rimbert a, b, c, Matthieu Pichelin a, b, c, d, e, Simon Lecointe a, b, c, d, Marie Marrec d, e, \\ Solena Le Scouarnec a, b, c, Elias Barrak a, b, c, d, Mikael Croyal ${ }^{\mathrm{f}}$, Michel Krempf c, d, f, \\ Hervé Le Marec a, b, c, d, Richard Redon a, b, c, d, Jean-Jacques Schott a, b, c, d, **, \\ Jocelyne Magré a, b, c, Bertrand Cariou a, b, c, d, e,* \\ a INSERM, UMR1087, l'institut du thorax, Nantes, F-44000, France \\ b CNRS, UMR 6291, Nantes, F-44000, France \\ ${ }^{\mathrm{c}}$ Université de Nantes, Nantes, F-44000, France \\ ${ }^{\mathrm{d}}$ CHU Nantes, l'institut du Thorax, Nantes, F-44000, France \\ e CIC Thorax, CHU Nantes, l'institut du Thorax, Nantes, F-44000, France \\ ${ }^{\mathrm{f}}$ Centre de Recherche en Nutrition Humaine de l'Ouest (CRNHO, INRA UMR1280), Nantes, F-44093, France
}

\section{A R T I C L E I N F O}

\section{Article history:}

Received 18 November 2015

Received in revised form

8 April 2016

Accepted 8 April 2016

Available online 11 April 2016

\section{Keywords:}

Familial hypobetalipoproteinemia

Target next generation sequencing

APOB

PCSK9

Molecular diagnosis

\begin{abstract}
A B S T R A C T
Background and aims: Familial hypobetalipoproteinemia (FHBL) is a co-dominant disorder characterized by decreased plasma levels of LDL-cholesterol and apolipoprotein B (ApoB). Currently, genetic diagnosis in FHBL relies largely on Sanger sequencing to identify APOB and PCSK9 gene mutations and on western blotting to detect truncated ApoB species.

Methods: Here, we applied targeted enrichment and next-generation sequencing (NGS) on a panel of three FHBL genes and two abetalipoproteinemia genes (APOB, PCSK9, ANGPTL3, MTTP and SAR1B). Results: In this study, we identified five likely pathogenic heterozygous rare variants. These include four novel nonsense mutations in $A P O B$ (p.Gln845*, p.Gln2571*, p.Cys2933* and p.Ser3718*) and a rare variant in PCSK9 (Minor Allele Frequency $<0.1 \%$ ). The affected family members tested were shown to be carriers, suggesting co-segregation with low LDL-C.

Conclusions: Our study further demonstrates that NGS is a reliable and practical approach for the molecular screening of FHBL-causative genes that may provide a mean for deciphering the genetic basis in FHBL.
\end{abstract}

(c) 2016 Published by Elsevier Ireland Ltd.

\section{Introduction}

Familial hypobetalipoproteinemia (FHBL) belongs to a heterogeneous group of monogenic disorders characterized by reduced plasma levels of low-density lipoprotein cholesterol (LDLC) and apolipoprotein $\mathrm{B}(\mathrm{ApoB})$ below the fifth percentile for age and sex in the population. FHBL is a co-dominant disorder whose frequency

\footnotetext{
* Corresponding author. Clinique d'Endocrinologie, l'Institut du Thorax, Hôpital Guillaume \& René Laennec, Boulevard Jacques Monod, 44093 Nantes cedex, France. ** Corresponding author. INSERM UMR 1087-CNRS UMR6291, L'institut du thorax, IRS-UN, 8 quai Moncousu, BP70721, 44007 Nantes Cedex 1, France.

E-mail addresses: jjschott@univ-nantes.fr (J.-J. Schott), bertrand.cariou@univnantes.fr (B. Cariou).
}

in the heterozygous form is estimated to be 1:1000-1:3000 [1,2]. FHBL heterozygotes may be asymptomatic or have some clinical manifestations such as liver steatosis. Furthermore, FHBL has been associated with a longevity syndrome linked to cardiovascular protection $[1,2]$. FHBL is genetically heterogeneous and may be due to loss-of-function mutations in $A P O B[1,2]$, or less frequently in PCSK9, which encodes the proprotein convertase subtilisin/kexin type 9 [3-5]. In addition, familial combined hypolipidemia - which is characterized by low levels of LDL-C, high-density lipoprotein cholesterol (HDL-C) and triglycerides (TG) can be caused by mutations in the angiopoietin-like 3 gene (ANGPTL3) [6,7]. Despite previous gene discoveries, the genetic etiology of FHBL remains to be determined in approximately $50 \%$ of cases $[1,8]$.

Currently, genetic diagnosis in FHBL relies largely on Sanger 
sequencing of $A P O B$. Because $A P O B$ is a large gene composed of 29 exons covering $14,121 \mathrm{bp}$, Western-blotting may be used to detect truncated protein species that are $>30 \%$ of full-length protein size $[1,2]$. When Western blotting is negative, sequencing the 25 first exons of $A P O B$ gene (exons 1 to 25 ) - a time consuming and costly approach - is mandatory $[9,10]$. Next-generation sequencing (NGS) technologies enable rapid and cost-effective sequencing of targeted genomic regions. NGS is thus a powerful approach for genetic diagnostics in inherited Mendelian disorders [11,12]. In the present study, we developed a targeted resequencing panel to screen for coding variations amongst three known FHBL and two abetalipoproteinemia $(\mathrm{ABL})$ genes. Re-sequencing these genes in eight unrelated individuals with FHBL revealed four novel missense mutations in $A P O B$ that segregate with the low LDL-C trait in related individuals as well as one likely pathogenic mutation in PCSK9.

\section{Patients and methods}

\subsection{Study approval}

The study (NCT02354079) was conducted in compliance with current Good Clinical Practice standards. We obtained informed consent from individuals involved in the study and approval from local institutional ethics committees (CPP OUEST IV 49/14).

\subsection{Patient recruitment and clinical evaluation}

Eight unrelated individuals routinely followed for FHBL in the department of endocrinology at Nantes University Hospital have been recruited. In the probands, FHBL diagnosis was based on low levels of fasting calculated plasma LDL-C $<50 \mathrm{mg} / \mathrm{dL}$ without lipid lowering therapy. Fasting lipid profile (total cholesterol, HDL-C, LDL-C and TG) and ApoB levels were also determined in some of their relatives. Affected relatives were diagnosed by $\mathrm{LDL}-\mathrm{C}<80 \mathrm{mg} /$ $\mathrm{dL}$ and/or ApoB $<50 \mathrm{mg} / \mathrm{dL}$. Anthropometric data, biochemical tests and abdominal ultrasonography were recorded.

\subsection{Capture design and library preparation}

We developed a re-sequencing custom design based on the HaloPlex $^{\mathrm{TM}}$ Target Enrichment system (Agilent Technologies) to perform high-throughput sequencing of the coding regions of genes previously linked to FHBL (APOB, PCSK9, ANGPTL3) and ABL (MTTP, SAR1B) encoding the Microsomal Triglyceride Transfer Protein and the Secretion Associated, Ras related GTPase 1B, respectively). Targeted coding regions (exons + about 10-bp non coding flanking sequences) correspond to $22.83 \mathrm{~kb}$ of genomic sequence. Sequencing (100-bp paired-end reads) was performed on Illumina HiSeq 2500 station.

\subsection{Variant calling and filtering}

Raw sequence reads were aligned to the human reference genome (GRCh37) using BWA-MEM (version 0.7.5a) after removing sequences corresponding to Illumina adapters with Cutadapt (v1.2). Variants were called for each sample separately using GATK UnifiedGenotyper (version 2.8) and Samtools mpileup (version 0.1.19): they were considered for further analyses when found by both algorithms. Variants frequency was determined using the Exome Aggregation Consortium database (Exac.broadinstitute.org/): they were considered as rare when the minor allele frequency (MAF) was lower than $0.1 \%$ in the non-Finnish European population. The potential effect of variants was determined using Variant Effect Predictor annotations (Ensembl). Filtering was performed using Knime4Bio [13].

\subsection{Validation (visualization and Sanger sequencing)}

All relevant variants identified in the eight patients were reviewed by visual inspection of sequence reads using the Integrative Genomics Viewer [14]. Sanger sequencing was performed for validation and co-segregation analysis among family members. Regions of interest were amplified by polymerase chain reaction and sequenced with the dye-terminator chemistry (ABI PRISM 3730, Applied Biosystems, Foster City, CA).

\subsection{Dosage of lipoproteins in plasma}

Plasma levels of ApoA-I, ApoA-II, ApoB-100, ApoC-II, ApoC-III, ApoE and $\mathrm{Lp}(\mathrm{a})$ were measured using the multiplexed LC/MS/MS method as previously described [15].

\subsection{Lipoprotein separation and $A p o B$ western blotting}

The LDL plasmatic fractions were obtained by ultracentrifugation separation protocol [16]. $50 \mu \mathrm{g}$ of extracted proteins were separated by SDS-PAGE and transferred to a nitrocellulose membrane. Immunoblots probed with polyclonal antibody ApoB-100 (AB742) (1:1000) and HRP-conjugated antibodies (rabbit antigoat IgG-HRP: sc-2768) $(1: 10,000)$ were purchased from Merck Millipore and Santa-Cruz biotechnology respectively.

\section{Results}

\subsection{Targeted resequencing}

Eight patients followed for FHBL in our clinical department have been included in this study. Their plasma lipid panels are listed in the Supplemental Table 1. Five genes were sequenced using the custom capture design that we developed based on the HaloPlex ${ }^{\mathrm{TM}}$ technology. The mean coverage depth was 201X $( \pm 90)$ per sample with $98 \%$ of the target regions being covered at least 10 times $(96.1 \%$ covered at least 20 times). Mean coverage depths throughout the five target genes are shown in Supplemental Fig. 1.

We identified five heterozygous rare variants (MAF $<0.1 \%$ ) that alter ApoB or PCSK9 protein sequence. The four $A P O B$ variants (p.Gln845*, p.Gln2571*, p.Cys2933* and p.Ser3718*) are likely pathogenic nonsense variants (SO: 0001587 stop gained) that are absent from the ExAC database.

The PCSK9-c.523 G > A variant was reported twice in the ExAC database (65,770 non-Finnish European population alleles). Predicted functional consequences of this variant either lead to: -a PCSK9 p.Asp175Asn missense variant (SO: 0001583) respectively annotated as tolerated or benign by SIFT/PolyPhen algorithms and displaying low conservation scores (CADD score $=-0.226944$ and GERP score $=-1.33$ ) or to - a splice variant (SO: 0001630), that leads to a frameshift followed by a premature stop codon PCSK9p.Asp175Serfs* 13 .

No variant was identified in the three other targeted genes according to our filtering criteria.

\subsection{Identified variants co-segregate with $F H B L$}

Segregation analysis of the $A P O B$ variants were performed in proband's family members when available (Fig. 1). Patients' clinical and biological characteristics are reported in Table 1.

The first $A P O B$ variant (Chr2:21,246,468; c.2533G > A; $A P O B-$ p.Gln845*) was identified in a 49 years-old woman (II:2/Family I) presenting low LDL-C $(20 \mathrm{mg} / \mathrm{dL})$. The proband's sons (III:1 and III:2) who had low LDL-C levels harbor the mutation. The youngest boy (III:2) also exhibited hepatic steatosis without increased liver 
A

Family II

।

II

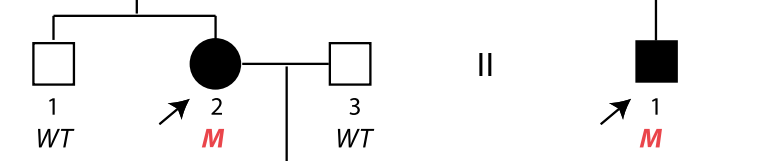

III
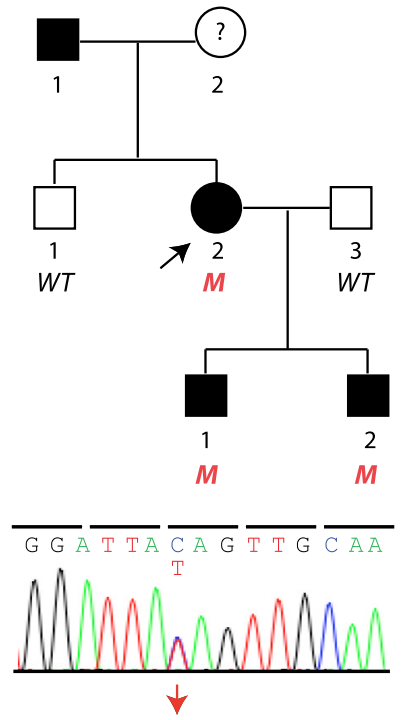

APOB-p.Gln845*

B

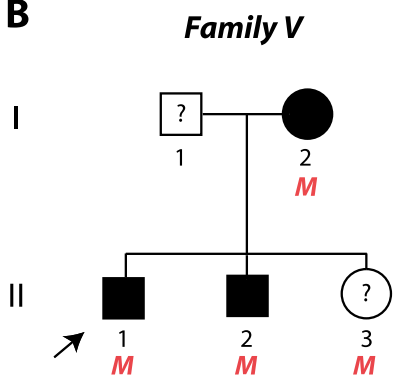

$\frac{\text { Exon } 3}{\mathrm{C} \mathrm{C} \mathrm{C}} \frac{}{\mathrm{C} \mathrm{C} \mathrm{C}} \overline{\mathrm{G}} \frac{\text { Intron } 3}{g \operatorname{tatagaC}}$

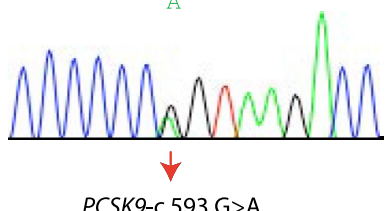

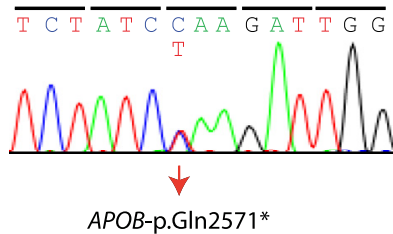

APOB-p.Gln $2571 *$
C
Family III

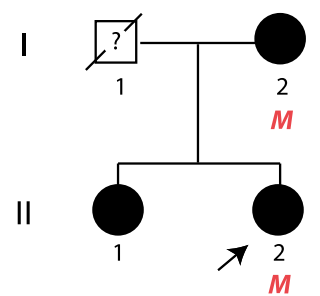

Family IV

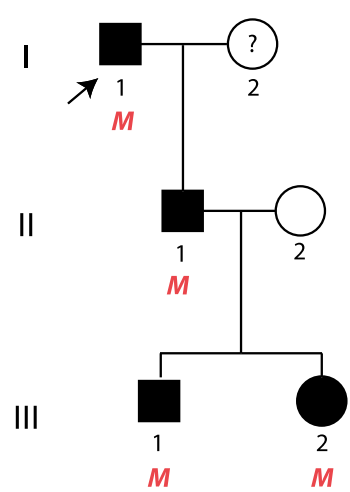

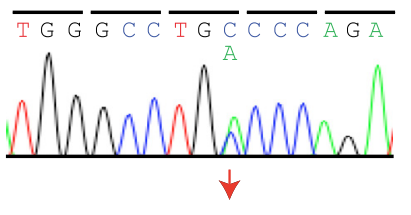

APOB-p.Cys2933*

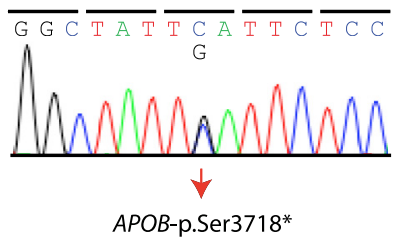

APOB-p.Ser3718*

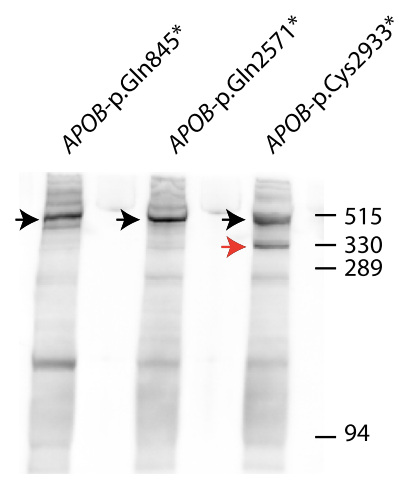

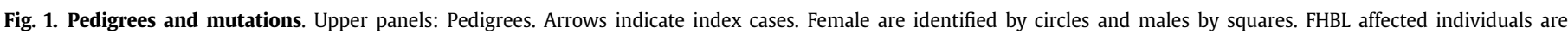

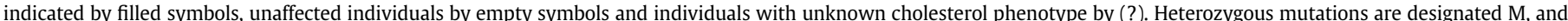

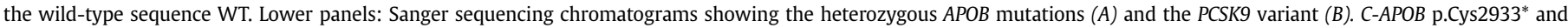

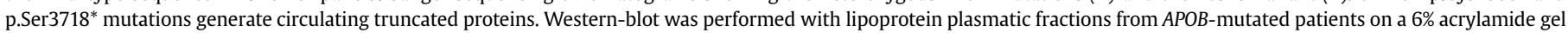

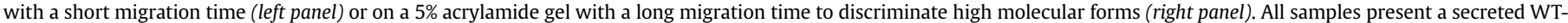

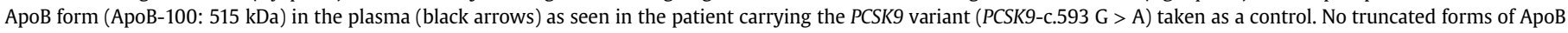

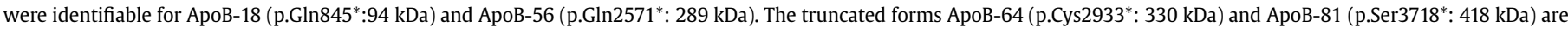
visible (red arrow) at the expected molecular weights.

enzymes. The two family members who did not carry the variant presented normal LDL-C levels. Interestingly, the proband's paternal grandfather died late in life ( $>95$ years), potentially suggesting a longevity syndrome as previously described in FHBL [1,2].

The second $A P O B$ variant (Chr2:21,232,029; c.7711G > A; $A P O B-$ p.Gln2571*) was identified in a 41 years-old man (II:1/Family II) who had low LDL-C (38 mg/dL), pre-diabetes and liver steatosis. DNA from his family was not available for segregation analyses.

The third $A P O B$ variant (Chr2:21,230,941; c.8799 G > T; APOBp.Cys2933*) was identified in a 24 years-old woman (II:2/Family III) who showed low LDL-C (28 mg/dL). Her mother (I:2) and sister
(II:1) also had low LDL-C. The proband's mother harbor the APOBp.Cys2933* variant.

The fourth $A P O B$ variant (Chr2:21,228,587; c.11153 G > C; APOBp.Ser3718*) was identified in an 84 years-old man (I:1/Family IV) who showed a low LDL-C level $(33 \mathrm{mg} / \mathrm{dL})$. The three other affected members of the family, his son (II:1) and great-children (III:1 and III:2) with low LDL-C levels harbor the APOB-p.Ser3718* variant. Subject II-1 also had type 2 diabetes and severe non-alcoholic steatohepatitis (NASH) with precirrhotic lesions and welldifferentiated hepatocellular carcinoma (HCC) diagnosed on liver biopsy. 
Table 1

Main biological features and mutations of FHBL family members.

\begin{tabular}{|c|c|c|c|c|c|c|c|c|c|c|c|c|c|c|c|c|}
\hline & Age & Gender & BMI & Diabetes & $\begin{array}{l}\mathrm{TC}(\mathrm{mg} / \\
\mathrm{dL})\end{array}$ & $\begin{array}{l}\text { LDL-C (mg/ } \\
\mathrm{dL})\end{array}$ & $\begin{array}{l}\text { HDL-C (mg/ } \\
\mathrm{dL})\end{array}$ & $\begin{array}{l}\mathrm{TG}(\mathrm{mg} / \\
\mathrm{dL})\end{array}$ & $\begin{array}{l}\text { FPG } \\
(\mathrm{mmol} / \mathrm{L})\end{array}$ & $\begin{array}{l}\text { HbA1C } \\
(\%)\end{array}$ & $\begin{array}{l}\text { AST } \\
(\mathrm{ULN})\end{array}$ & $\begin{array}{l}\text { ALT } \\
(\text { ULN) }\end{array}$ & $\begin{array}{l}\text { GGT } \\
(\mathrm{ULN})\end{array}$ & $\begin{array}{l}\text { ALP } \\
(\text { ULN) }\end{array}$ & $\begin{array}{l}\text { Liver } \\
\text { steatosis }\end{array}$ & $\begin{array}{l}\text { Molecular } \\
\text { alteration }\end{array}$ \\
\hline \multicolumn{17}{|c|}{ Family I } \\
\hline $\mathrm{I}: 1$ & 83 & M & n.a. & n.a. & n.a. & 58 & n.a. & n.a. & n.a. & n.a. & n.a. & n.a. & n.a. & n.a. & n.a. & n.a. \\
\hline II:1 & 51 & M & n.a. & n.a. & 207 & 135 & 51 & 102 & n.a. & n.a. & 0.52 & 0.64 & 0.35 & 0.71 & n.a. & WT \\
\hline II:2 & 49 & $\mathrm{~F}$ & 20 & No & 143 & 20 & 120 & 18 & 4.7 & 5.0 & 0.66 & 0.74 & 0.38 & 0.39 & $\mathrm{~N}$ & $\begin{array}{l}A P O B- \\
\text { p.Gln } 845^{*}\end{array}$ \\
\hline II:3 & 48 & $\mathrm{M}$ & n.a. & n.a. & 230 & 155 & 52 & 117 & n.a. & n.a. & n.a. & n.a. & n.a. & n.a. & n.a. & WT \\
\hline III:1 & 17 & M & 18 & No & 98 & 14 & 79 & 25 & n.a. & n.a. & 0.40 & 0.32 & 0.42 & 0.37 & n.a. & $\begin{array}{l}A P O B- \\
\text { p.Gln } 845^{*}\end{array}$ \\
\hline III:2 & 15 & M & 18 & No & 104 & 7 & 91 & 31 & n.a. & n.a. & 0.55 & 0.46 & 0.30 & 0.63 & $\mathrm{Y}$ & $\begin{array}{l}A P O B- \\
\text { p.GIn845* }\end{array}$ \\
\hline \multicolumn{17}{|c|}{ Family II } \\
\hline II:1 & 40 & M & 34 & Prediabetes & 113 & 38 & 69 & 32 & 7.2 & 5.9 & 0.8 & 1.34 & 0.47 & 0.36 & $\mathrm{Y}$ & $\begin{array}{l}A P O B- \\
\text { p.Gln2571* }\end{array}$ \\
\hline \multicolumn{17}{|c|}{ Family III } \\
\hline $\mathrm{I}: 2$ & 61 & $\mathrm{~F}$ & 24 & No & 145 & 55 & 81 & 45 & 4.9 & 5.9 & 1.08 & 1.03 & 0.55 & 0.54 & n.a. & $\begin{array}{l}A P O B- \\
\text { pCys2933* }\end{array}$ \\
\hline II:1 & 39 & $\mathrm{~F}$ & n.a. & n.a. & 166 & 17 & 147 & 12 & n.a. & n.a. & n.a. & n.a. & n.a. & n.a. & n.a. & n.a. \\
\hline II:2 & 24 & $\mathrm{~F}$ & 27 & No & 143 & 28 & 110 & 26 & 4.2 & n.a. & 0.88 & 1.00 & 0.88 & 1.01 & n.a. & $\begin{array}{l}\text { APOB- } \\
\text { pCys2933* }\end{array}$ \\
\hline \multicolumn{17}{|c|}{ Family IV } \\
\hline $\mathrm{I}: 1$ & 84 & M & 26 & No & 106 & 33 & 60 & 60 & 4.7 & n.a. & 0.62 & 0.42 & 1.44 & 0.50 & $\mathrm{Y}$ & $\begin{array}{l}A P O B- \\
\text { p.Ser3718* }\end{array}$ \\
\hline II:1 & 58 & M & 34 & Yes & 123 & 40 & 68 & 75 & 7.2 & 6.5 & 2.34 & 2.26 & 11.73 & 0.47 & $\mathrm{Y}^{\mathrm{a}}$ & $\begin{array}{l}A P O B- \\
\text { p.Ser3718* }\end{array}$ \\
\hline II:2 & 58 & $\mathrm{~F}$ & n.a. & No & 250 & 142 & 98 & 50 & n.a. & n.a. & n.a. & n.a. & n.a. & n.a. & n.a. & n.a. \\
\hline III:1 & 26 & M & 21 & No & 102 & 36 & 57 & 46 & n.a. & 5.4 & 0.46 & 0.74 & 0.34 & 0.23 & n.a. & $\begin{array}{l}A P O B- \\
\text { p.Ser3718* }\end{array}$ \\
\hline III:2 & 18 & $\mathrm{~F}$ & 19 & No & 124 & 49 & 62 & 65 & n.a. & n.a. & n.a. & n.a. & n.a. & n.a. & $\mathrm{N}$ & $\begin{array}{l}A P O B- \\
\text { p.Ser3718* }\end{array}$ \\
\hline \multicolumn{17}{|c|}{ Family V } \\
\hline $\mathrm{I}: 2$ & 52 & $\mathrm{~F}$ & 22 & No & 132 & 63 & 55 & 72 & n.a. & 5.5 & 0.54 & 0.37 & 0.33 & 0.56 & n.a. & $\begin{array}{l}\text { PCSK9- } \\
\text { c.523G > A }\end{array}$ \\
\hline II:1 & 23 & M & 22 & No & 120 & 50 & 55 & 89 & 4.5 & n.a. & 0.53 & 0.29 & 0.18 & n.a. & n.a. & $\begin{array}{l}\text { PCSK9- } \\
\text { c.523G > A }\end{array}$ \\
\hline II:2 & 16 & M & 20 & No & 141 & 74 & 52 & 76 & 4.3 & n.a. & 1.05 & 0.54 & 0.41 & 0.32 & n.a. & $\begin{array}{l}\text { PCSK9- } \\
\text { c.523G > A }\end{array}$ \\
\hline II:3 & 13 & $\mathrm{~F}$ & n.a & n.a & n.a & n.a & n.a & n.a & n.a & n.a & n.a & n.a & n.a & n.a & n.a & $\begin{array}{l}\text { PCSK9- } \\
\text { c.523G > A }\end{array}$ \\
\hline
\end{tabular}

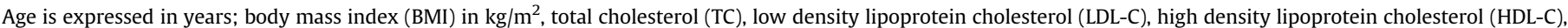

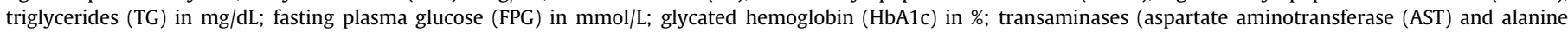

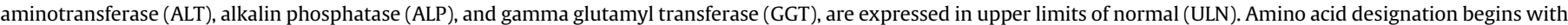
"1" at translation start codon 129 of APOB cDNA (Genbank entry NM_000384.2); F, female; M, male; WT, wild-type sequence; n.a., not available.

a Hepatocellular carcinoma.

The PCSK9 variant (Chr1:55,512,319; c.523 G > A; PCSK9) was identified in a 23 years-old man (II:1/Family V) with low LDL-C level $(50 \mathrm{mg} / \mathrm{dL}$ ). The proband's mother (I:2) and brother (II-2) who also had low LDL-C (63 $\mathrm{mg} / \mathrm{dL}$ and $74 \mathrm{mg} / \mathrm{dL}$ respectively) harbor the variant. The proband's sister (II:3) with unknown phenotype also harbor the variant.

\subsection{APOB-p.Cys $2933^{*}$ and p.Ser $3718^{*}$ mutations generate circulating truncated proteins}

$A P O B-p . G \ln 845^{*}$ and p.Gln2571* mutations can potentially generate truncated proteins with expected weight of $94 \mathrm{kDa}$ and $289 \mathrm{kDa}$ respectively. These truncated forms were not visible in plasma (Fig. 1C). APOB-p.Cys2933* and p.Ser3718* mutations lead to the formation of expected truncated ApoB forms (ApoB-64 and ApoB-81) of $330 \mathrm{kDa}$ and $418 \mathrm{kDa}$ (Fig. 1C, right panel) that can be secreted by the liver and lipidated.

\section{Discussion}

We have developed a targeted NGS approach to improve molecular diagnosis for FHBL. By testing this approach on a series of eight FHBL probands, we identified four heterozygous likely disease-causing $A P O B$ nonsense mutations. Our 50\% detection rate for $A P O B$ mutation is in line with previously reported $A P O B$ mutation prevalence in FHBL patients [8,1]. Liver steatosis was diagnosed in four patients from three families with $A P O B$ mutations, including one with severe NASH complicated by a HCC, reinforcing the hypothesis that some $A P O B$ mutations could lead to FHBL, liver cirrhosis and HCC [17]. We also identified a rare PCSK9-c.523 G > A variant that co-segregates with FHBL. Although in silico analyses predict a potential PCSK9 splice variant, further functional experiments are needed to determine whether this variant is associated with a PCSK9 loss-of-function.

$A P O B$ encodes a product containing 4563 amino acids and encompasses 29 exons. Over 90 mutations have been reported in subjects with FHBL, mostly nonsense and frameshift mutations and novel mutations are continually being identified. Moreover, missense mutations have been described in FHBL $[18,19]$ and could be missed by current genetic testing using western-blotting as a first-line approach. Because most unrelated FHBL kindreds carry private mutations and because there is no evidence for FHBL mutation hotspots, further development of reliable, high throughput and cost effective molecular screening approaches are needed. In the context of genetically heterogeneous diseases involving large genes, targeted resequencing technology has become an accurate, 
fast and cost effective approach, which is applicable in routine molecular clinical diagnosis $[20,21]$. Johansen et al. recently designed a large targeted resequencing panel to investigate 73 genes in patients presenting various forms of dyslipidemia and related metabolic disorders [12]. They demonstrated that - despite some limitations due to lower coverage depth for particular genomic regions and to the nondetection of genome structural variation - this panel allows the detection of most known mutations based on Sanger sequencing as well as high detection rates for coding mutations in previously unsequenced samples.

Interestingly, the patients carrying no disease-relevant variant in the known FHBL-susceptibility genes could be subjected to whole exome sequencing combined with exhaustive familial investigation, in order to identify new disease genes. The demonstration that PCSK9 loss-of-function mutations are associated with reduced cardiovascular events [22] has been the accelerator for the development of PCSK9 inhibitors. More recently, monoclonal antibodies directed against ANGTPL3 have demonstrated lipidlowering efficacy in monkeys [23]. In this context, comprehensive genetic resequencing ranging from exome to whole genome but also RNA sequencing could represent the first step towards identifying new drug targets in hypercholesterolemia.

\section{Acknowledgements}

We thank the patients and their families for their collaboration. We are also grateful to the members of the Center of Biological Ressources (CHU Nantes, Hôtel Dieu, CRB, Nantes, F-44093, France, BRIF: BB-0033-00040), the Genomics and Bioinformatics core facility of Nantes (Biogenouest) and the mass spectrometry core facility of Nantes (CRNH - Biogenouest). We thank M. Chétiveaux for her advices for ApoB Western blotting. This work was supported by the Fondation Leducq (grant\# 13CVD03), Fundazione Cariplo (grant\# 2012-0549), Région Pays de La Loire (VaCaRMe), Fondation Génavie and Fondation de France (grant\# 2015-00047967). A.R. was granted by the "Ministère de l'éducation nationale, de l'enseignement supérieur et de la recherche".

\section{Appendix A. Supplementary data}

Supplementary data related to this article can be found at http:// dx.doi.org/10.1016/j.atherosclerosis.2016.04.010.

\section{References}

[1] P. Tarugi, M. Averna, E. Leo, A. Cefalù, D. Noto, L. Magnolo, et al., Molecular diagnosis of hypobetalipoproteinemia: an ENID review, Atherosclerosis 195 (2007) 19-27.

[2] A.J. Hooper, J.R. Burnett, Update on primary hypobetalipoproteinemia, Curr. Atheroscler. Rep. 16 (2014) 423.

[3] B. Cariou, K. Ouguerram, Y. Zaïr, R. Guerois, C. Langhi, S. Kourimate, et al., PCSK9 dominant negative mutant results in increased LDL catabolic rate and familial hypobetalipoproteinemia, Arterioscler. Thromb. Vasc. Biol. 29 (2009) 2191-2197.

[4] K. Berge, L. Ose, T. Leren, Missense mutations in the PCSK9 gene are associated with hypocholesterolemia and possibly increased response to statin therapy, Arterioscler. Thromb. Vasc. Biol. 26 (2006) 1094-1100.

[5] T. Fasano, A.B. Cefalù, E. Di Leo, D. Noto, D. Pollaccia, L. Bocchi, V. Valenti, R. Bonardi, O. Guardamagna, M. Averna, P. Tarugi, A novel loss of function mutation of PCSK9 gene in white subjects with low-plasma low-density lipoprotein cholesterol, Arterioscler. Thromb. Vasc. Biol. 27 (2007) 677-681.

[6] X. Wang, D. Wang, Z. Shan, Clinical and genetic analysis of a family diagnosed with familial hypobetalipoproteinemia in which the proband was diagnosed with diabetes mellitus, Atherosclerosis 239 (2015) 552-556.

[7] K. Musunuru, J. Pirruccello, R. Do, G. Peloso, C. Guiducci, C. Sougnez, et al., Exome sequencing, ANGPTL3 mutations, and familial combined hypolipidemia, N. Engl. J. Med. 363 (2010) 2220-2227.

[8] S.W. Fouchier, R.R. Sankatsing, J. Peter, S. Castillo, M. Pocovi, R. Alonso, et al, High frequency of APOB gene mutations causing familial hypobetalipoproteinaemia in patients of Dutch and Spanish descent, J. Med. Genet. 42 (2005) e23.

[9] J. Burnett, D. Bell, A. Hooper, R. Hegele, Clinical utility gene card for: familial hypobetalipoproteinaemia (APOB) - update 2014, Eur. J. Hum. Genet. 23 (2015).

[10] J. Burnett, D. Bell, A. Hooper, R. Hegele, Clinical utility gene card for: abetalipoproteinaemia, Eur. J. Hum. Genet. 20 (2012).

[11] B. Sikkema-Raddatz, L. Johansson, E. Boer, R. Almomani, L. Boven, M. Berg, et al., Targeted next-generation sequencing can replace sanger sequencing in clinical diagnostics, Hum. Mutat. 34 (2013) 1035-1042.

[12] C.T. Johansen, J.B. Dubé, M.N. Loyzer, A. MacDonald, D.E. Carter, A.D. McIntyre, et al., LipidSeq: a next-generation clinical resequencing panel for monogenic dyslipidemias, J. Lipid Res. 55 (2014) 765-772.

[13] P. Lindenbaum, S. Scouarnec, V. Portero, R. Redon, Knime4Bio: a set of custom nodes for the interpretation of next-generation sequencing data with KNIME, Bioinformatics 27 (2011) 3200-3201.

[14] H. Thorvaldsdóttir, J. Robinson, J. Mesirov, Integrative genomics viewer (IGV): high-performance genomics data visualization and exploration, Brief. Bioinform. 14 (2013) 178-192.

[15] M. Croyal, F. Fall, V. Ferchaud-Roucher, M. Chétiveaux, Y. Zaïr, K. Ouguerram, M. Krempf, R. Nobécourt, Multiplexed peptide analysis for kinetic measurements of major human apolipoproteins by LC/MS/MS, J. Lipid Res. 57 (2016) 509-515.

[16] M.J. Chapman, S. Goldstein, D. Lagrange, P.M. Laplaud, A density gradient ultracentrifugal procedure for the isolation of the major lipoprotein classes from human serum, J. Lipid Res. 22 (1981) 339-358.

[17] A.B. Cefalù, J.P. Pirruccello, D. Noto, S. Gabriel, V. Valenti, N. Gupta, R. Spina P. Tarugi, S. Kathiresan, M.R. Averna, A novel APOB mutation identified by exome sequencing cosegregates with steatosis, liver cancer, and hypocholesterolemia, Arterioscler. Thromb. Vasc. Biol. 33 (2013) 2021-2025.

[18] J. Burnett, J. Shan, B. Miskie, A. Whitfield, J. Yuan, K. Tran, et al., A novel nontruncating APOB gene mutation, R463W, causes familial hypobetalipoproteinemia, J. Biol. Chem. 278 (2003) 13442-13452.

[19] A.J. Whitfield, G.M. Crawford, K. Robertson, P.H.R. Barrett, R.A. Hegele, K. Tran, et al., A novel non-truncating APOB gene mutation, L343V, causes familial hypobetalipoproteinaemia, Atheroscler. Suppl. 5 (2004) 78-79.

[20] J.L. Stoddard, J.E. Niemela, T.A. Fleisher, S.D. Rosenzweig, Targeted NGS: a costeffective approach to molecular diagnosis of PIDs, Front. Immunol. 5 (2014) 531.

[21] R.A. Hegele, M.R. Ban, H. Cao, A.D. McIntyre, J.F. Robinson, J. Wang, Targeted next-generation sequencing in monogenic dyslipidemias, Curr. Opin. Lipidol. 26 (2015) 103-113.

[22] J. Cohen, E. Boerwinkle, T. Mosley, H. Hobbs, Sequence variations in PCSK9, low LDL, and protection against coronary heart disease, N. Engl. J. Med. 354 (2006) 1264-1272.

[23] V. Gusarova, C.A. Alexa, Y. Wang, A. Rafique, J.H. Kim, D. Buckler, et al., ANGPTL3 blockade with a human monoclonal antibody reduces plasma lipids in dyslipidemic mice and monkeys, J. Lipid Res. 56 (2015) 1308-1317. 